\title{
CORPORATE INTEGRITY ANALYSIS VIA DECISION SUPPORT SYSTEM (DSS): EVIDENCE FROM MALAYSIAN ORGANIZATION
}

\author{
Ayub Md Som ${ }^{1}$, Rafidah Zainal ${ }^{2}$, \\ Nafsiah Mohamed ${ }^{2}$ and Sherif Abdulbari Ali ${ }^{3}$ \\ ${ }^{1}$ Accounting Research Institute and Faculty of Chemical Engineering, \\ Universiti Teknologi MARA, Selangor, Malaysia \\ E-mail: ayub522@uitm.edu.my \\ ${ }^{2}$ Accounting Research Institute, \\ Universiti Teknologi MARA, Selangor, Malaysia \\ ${ }^{3}$ Faculty of Chemical Engineering, \\ Universiti Teknologi MARA, Selangor, Malaysia
}

\begin{abstract}
With increased awareness towards ethics and integrity in Malaysia, the government through the Integrity Institute of Malaysia (IIM) had refined the scale of the original tool to reflect the local context with the development of the Corporate Integrity Assessment Questionnaire (CIAQ), which was later known as the Corporate Integrity System Malaysia (CISM ${ }^{\mathrm{TM}}$ ). CISM was a mere questionnaire consisting of 12 dimensions with 214 questions. This study attempted to develop a prototype tool using an expert system methodology coupled with its own software architecture and computer programming by incorporating all elements in CIAQ, in order to analyze the current level of implementation stage of the CISM ${ }^{\mathrm{TM}}$ in an organization. For the purpose of this work, Organization A was included as a case study and the results showed that the organization had an integrity level of between $50 \%$ to $75 \%$. This clearly indicates that the organization is very likely in the right direction to implement ethics and integrity at the work place. Consequently, the tool is also able to provide some recommendations in the form of a decision support system for future improvements in the organization.
\end{abstract}

Keywords: corporate integrity, ethics, decision support system, expert systems, software architecture

$\underline{\text { ARTICLE INFO }}$

Article History:

Received: 11 July 2019

Accepted: 4 November 2019

Published: 31 December 2019 


\section{INTRODUCTION}

According to Transparency International (TI) based in Germany, the Corruption Perception Index for Malaysia is currently at $45 / 100$, which is ranked $62^{\text {nd }}$ in the world. Changes in the economic and political environment can contribute to corruption and fraud phenomenon. This is because growing consensus in both the academic and policy circles could impart negative impacts on corruption in socio-economic development (Siddiquee, 2010). Apparently, government and international agencies have focused more towards looking for effective measures to control this threat. For instance, in 2004, the Malaysian government introduced the National Integrity Plan (NIP) that acted as a master plan to guide all sectors including both public and private organizations in an integrated and coordinated manner to enhance integrity. Even with existing policies and anti-corruption laws, these issues are often ignored in practice. At the international level, the global ethics and integrity benchmark (GEIB), by Joan Elise Dubinsky from the United States of America existing since 2008, has long been adopted to measure ethics and integrity at the work place (Dubinsky \& Richter, 2008). With increasing awareness towards ethics and integrity in Malaysia, IIM together with the help of a group of Malaysian academics had subsequently refined the scale of the original tool to reflect local context with the development of the Corporate Integrity Assessment Questionnaire (CIAQ), which was later known as a Corporate Integrity System Malaysia (CISM $\left.{ }^{\mathrm{TM}}\right)$. On that account, the Corporate Integrity Pledge (CIP) was launched in 2011 for companies to show their resolution to fight corruption. However, CISM ${ }^{\mathrm{TM}}$ is a mere questionnaire which consists of 12 dimensions with a total of 214 questions. Therefore, an in-depth assessment of the integrity level is essential in building a transparent nation.

Leading into $4^{\text {th }}$ Industrial Revolution (IR4.0) that emphasizes on Internet of Things, an assessment using a software is a must in getting attention from the world. There are a lot of analytical software used in the Social Science Field such as the spreadsheet tool, forensic analytic tool, text analytics, and expert systems (Zainal, Som \& Mohamed, 2017). In the Accounting and Business fields, for instance, all data are in a large volume; therefore, it is very difficult for an auditor to analyse it manually. With the advanced development in analytical software, previous workloads that require lengthy hours could be finished in a few minutes, nowadays. 
The data mining approach has shown to be a proactive decision support system (DSS) concept in preventing and predicting crime (Mohamad Noor, Ab Hamid, Mohemad, Abdul Jali, \& Hitam, 2015). By using the DSS, the time taken to detect fraud is much faster than other tools and it can be fully equipped with preventive measures. Nevertheless, research in DSS has been distanced from professional practice and it merely addresses an overly narrow range of concepts and issues. These fundamental, seemingly fatal problems have not been widely acknowledged, although some researchers have raised their concerns. (Arnott, Pervan, Donnell, \& Dodson, 2000). On this note, a solid motivation is urgently required to embark on this study to employ the DSS theory for corporate integrity analysis purposes.

The Malaysian Integrity Test (MIT) is currently one of the existing tools designated to measure integrity and predict the likelihood of problematic behaviour at work (MIMOS Malaysian Integrity Test (Mi-PBT MIT), 2013). However, it is merely a self-assessment tool to assess an individual and not for the whole organization. The Local Integrity Assessment (LIS) toolkit has been developed by the German-based Transparency International (TI) to assess the existence and effectiveness of procedures and mechanisms to promote transparency, accountability and integrity to fight corruption at the local level (McDevitt, 2014). Although a limited number of assessment tools are available in the literature to measure integrity, to the best of the authors' knowledge, a DSS software to measure integrity is still not available.

Currently, the analysis of the CIAQ is through an excel spreadsheet as practiced by the Integrity Institute of Malaysia (IIM). It takes a longer time to analyse and produce results. With the introduction of this tool, a complete analysis could be ready in a shorter time thus producing more structured results. Not only that, the tool is fully equipped with a user-friendly interface, which makes it easier for the user to attend to each question as well as to carry out an in-depth analysis for each dimension. These will certainly help the user to make decisions so as to improve their performance in the future.

Therefore, there is an urgent need to develop a decision support system, which can analyse ethics and integrity at the work place and at the same time give some recommendations in the form of an advisory system to enhance ethics and integrity implementation in an organization. This study attempted to develop a prototype tool, which employed the DSS methodology 
coupled with its own software architecture and computer programming by incorporating all elements in the CIAQ, capable of analysing the current level of implementation stage of the CISM $^{\mathrm{TM}}$ in an organization and providing some recommendations in the form of a decision support system for future improvement. This study will potentially contribute to software architecture development for upcoming research in financial criminology.

\section{LITERATURE REVIEW}

CIAQ is a tool to assess and measure progress in making a formal and transparent commitment to ethics and integrity at the workplace. It consists of twelve dimensions in which each dimension has its own descriptors making a total of 214 items as shown in Figure 1 and Table 1.

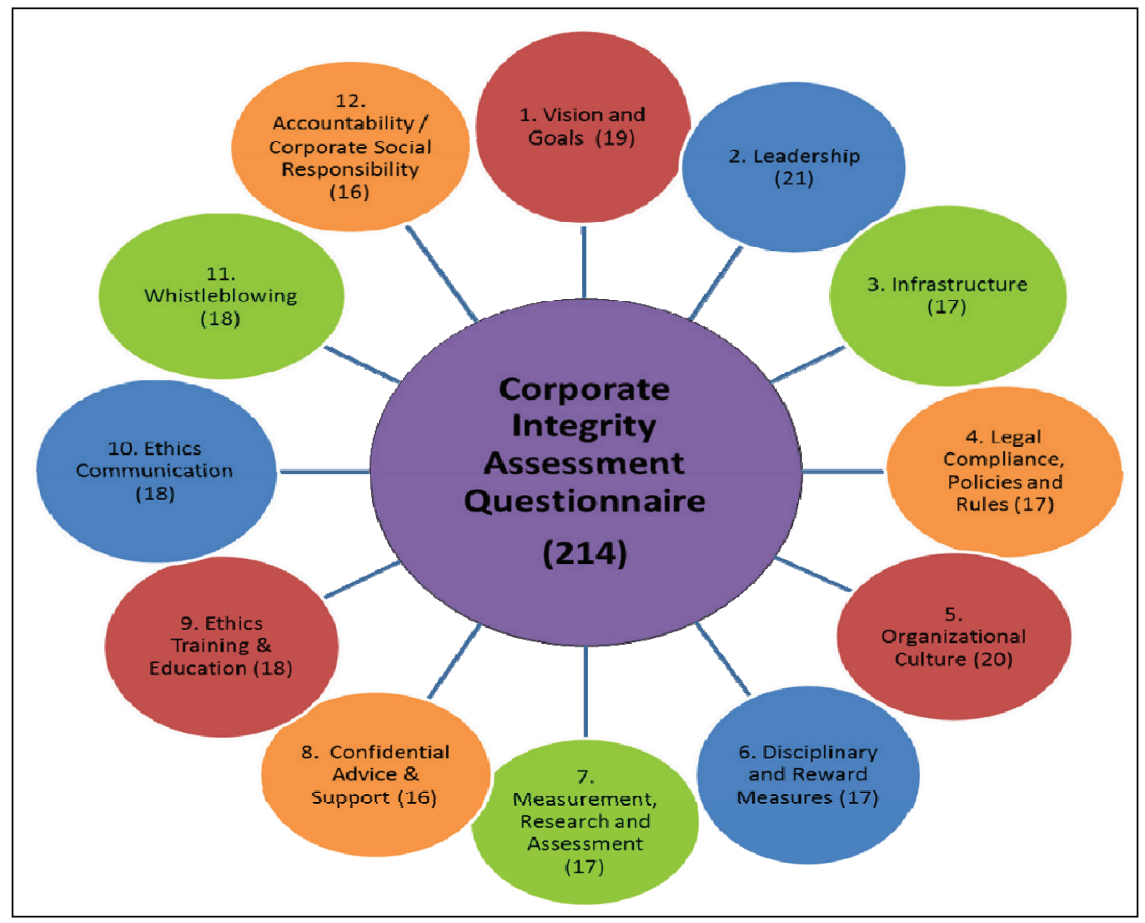

Figure 1: Corporate Integrity Assessment Questionnaire (CIAQ)

(Source: (Said \& Omar, 2014); (Sajari et al., 2016); (Sajari, Haron, \& Ismail, 2017)) 
Table 1: Dimensions and Descriptions of CIAQ

\begin{tabular}{cl}
\hline Dimension & \multicolumn{1}{c}{ Description } \\
\hline 1 & Organization overall concept and approach towards integrity \\
2 & Tone from the top-leaders and managers accountability \\
3 & Oganization structures or organises its function, effectively \\
4 & Legal frameworks include compliance, policies and rules \\
5 & Addresses organizational culture in mission, vision, goals \\
6 & Addresses rewards, punishment, incentives, disciplinary action \\
7 & Evaluates how integrity is measured, researched and assessed \\
8 & Describes how organization provide confidential advice \& support \\
9 & Awareness on ethics, education \& training are systematically \\
10 & embedded \\
11 & Covers how organization defines its stakeholders \& audiences \\
12 & Efforts to establish links with and invest in community, stakeholders, \\
& etc
\end{tabular}

Source: (Said \& Omar, 2014); (Sajari et al., 2016); (Sajari, Haron, \& Ismail, 2017)

For each dimension, a five level benchmark was sub-grouped to indicate progress towards best practices in that dimension. For the purpose of this study, the CIAQ was then used and subsequently benchmarked to the GEIB based on a five-band level, namely $0 \%$ (no integrity), $0 \%$ to $25 \%$ (symbolic actions only), 25\% to 50\% (partially implemented), $50 \%$ to $75 \%$ (systematically implemented), and $75 \%$ to $100 \%$ (best practices).

\section{METHODOLOGY}

An organization denoted as Organization A was included as a case study to carry out the research. Table 2 shows demographic profiles of the organization.

Table 2: Demographic Profiles of Organization A

\begin{tabular}{c}
\hline Organization A \\
\hline 179 Respondents \\
Breakdowns of respondents: \\
$60 \%$ Assistant Managers \\
$13 \%$ Head of Departments \\
$11 \%$ Managers \\
$16 \%$ Other positions \\
\hline
\end{tabular}


In CIAQ, 5-point Linkert scale was used in analysing all 214 questions, which were made available through an online session via the Survey Monkey ${ }^{\circledR}$. Its weightage scores were namely; 0 as 'not sure', 1 as 'strongly disagree', 2 as 'disagree', 3 as 'agree', and 4 as 'strongly agree'. There were also negative responses inserted by the respondent, and these were dealt as a negative multiplier. All responses pertaining to scores 1 and 2 were added together to denote as 'at least disagree'; whereas all responses pertaining to scores 3 and 4 were added together to denote as 'at least agree'. These tasks were then coded within a Microsoft Excel Spreadsheet and Visual Basics (VB) programming.

In the development stage of the DSS, the expert system methodology was employed as shown in Figure 2. It consisted of knowledge acquisition, knowledge-based construction, expert system development, $\alpha$-prototyped system development, and verification analysis with case studies or $\beta$-prototyped system development. In order to develop the DSS, a software architecture also known as a heart of the system, needs to be first designed as shown in Figure 3. It was divided into three major components which were namely; 'input' (all 12 dimensions plus 214 questions and demographic profiles), 'user interface' (its own inference engine and user interface design), and 'output' (current integrity level plus recommendations). 


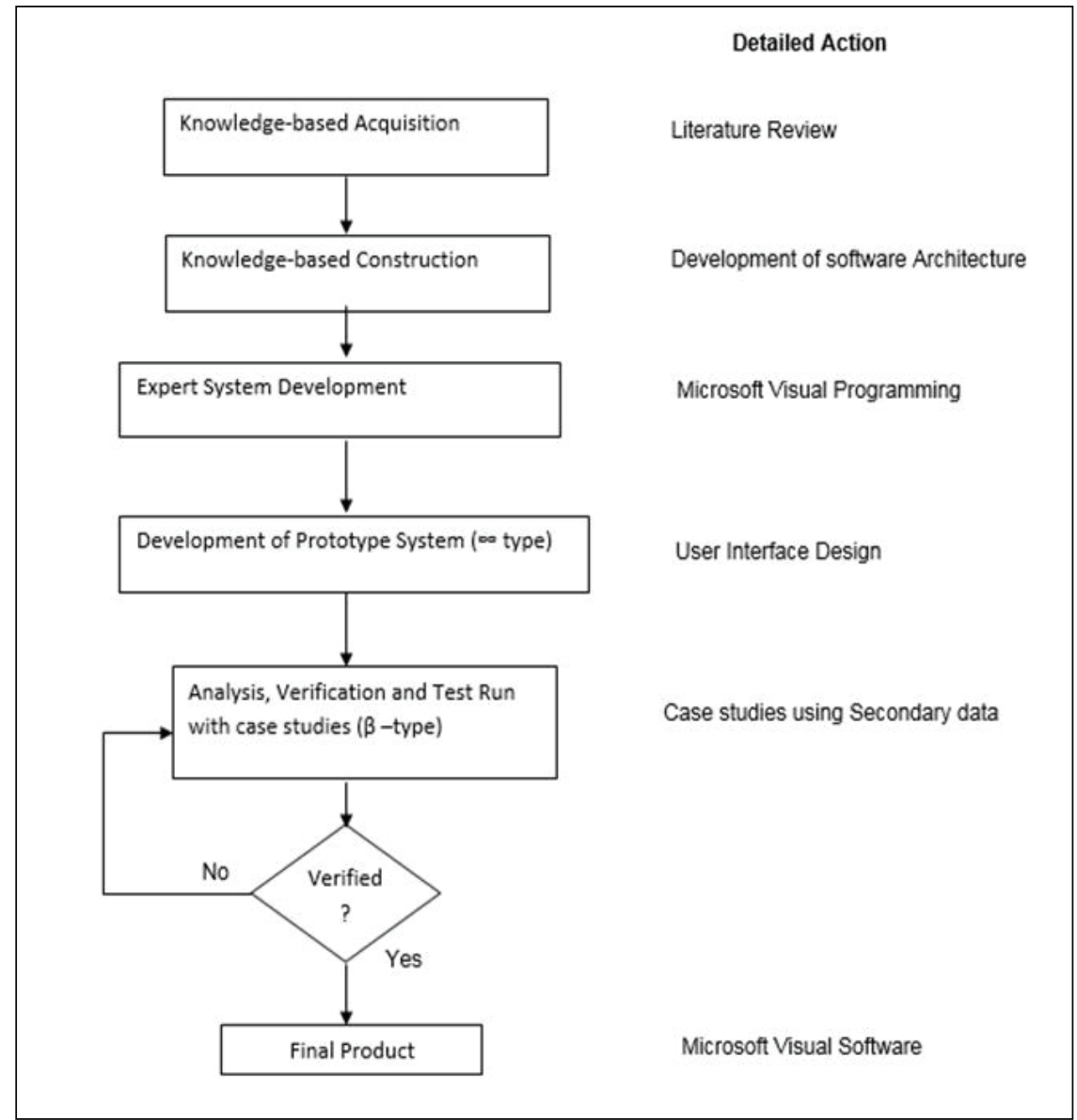

Figure 2: Expert System Methodology of the DSS 


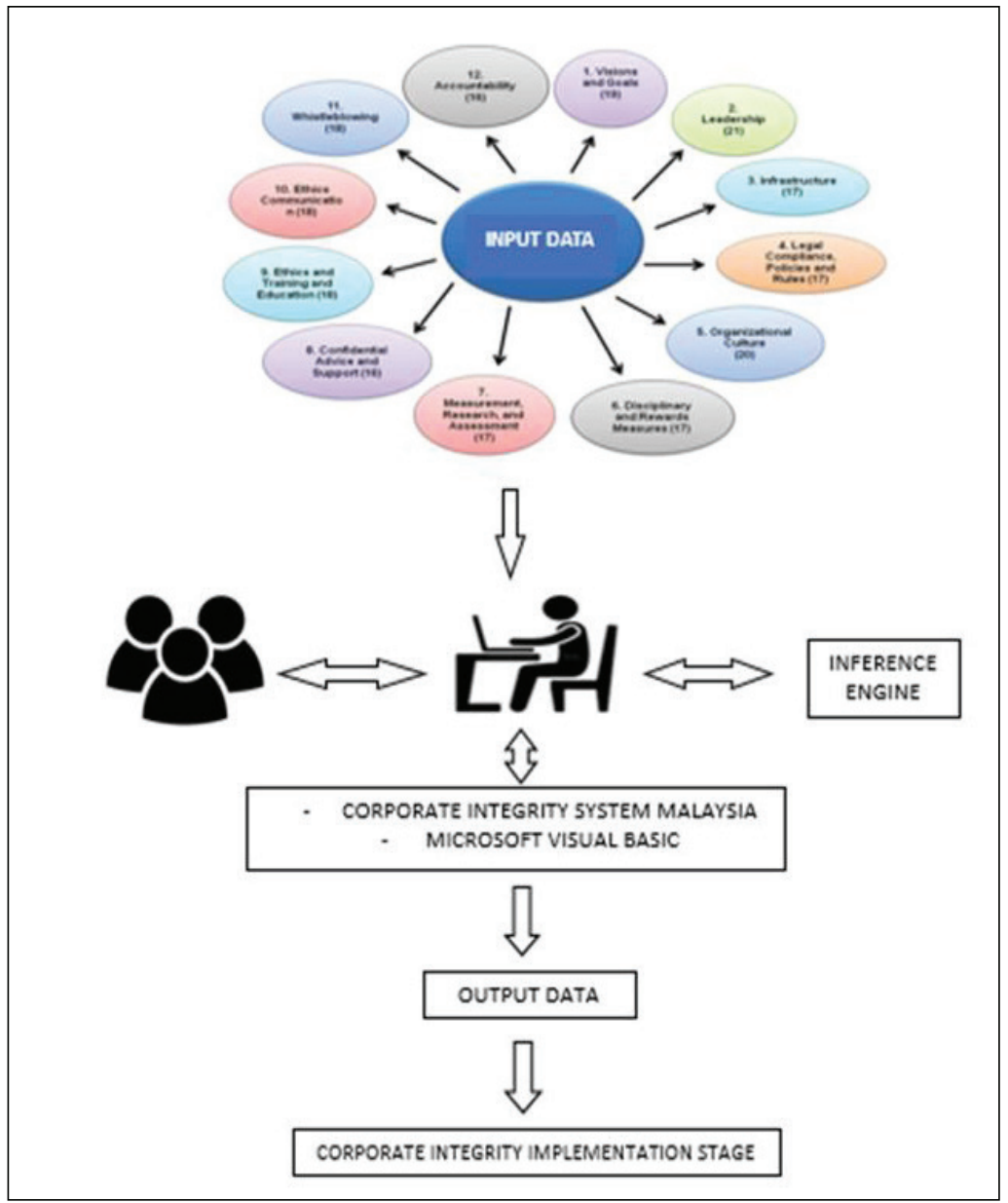

Figure 3: Software Architecture of the DSS

\section{RESULTS AND DISCUSSION}

The Corporate Integrity Analysis via the DSS was as an intelligent tool to analyse the CISM ${ }^{\mathrm{TM}}$. The tool was capable of analysing data gathered from the $\mathrm{CISM}^{\mathrm{TM}}$. It was then interpreted into graphical representation and ultimately was compared to the GEIB by means of five bands namely; at $0 \%$ (none), $25 \%$ (symbolic action), 50\% (partially implemented), $75 \%$ (systematically implemented) and 100\% (best practices). 
Figure 4 shows the general layout and the menu of the DSS. Meanwhile, Figure 5 shows user interfaces and results of the DSS implementation. As shown in both figures, respondent entries from each dimension with respective questions and their scores were taken from online surveys. These extracted data were then transferred into Excel Spreadsheet and VB platforms in order to execute and perform subsequent calculations for the ethics and integrity implementation level in the organization. For each dimension, an individual graph was plotted as shown in Figure 5.

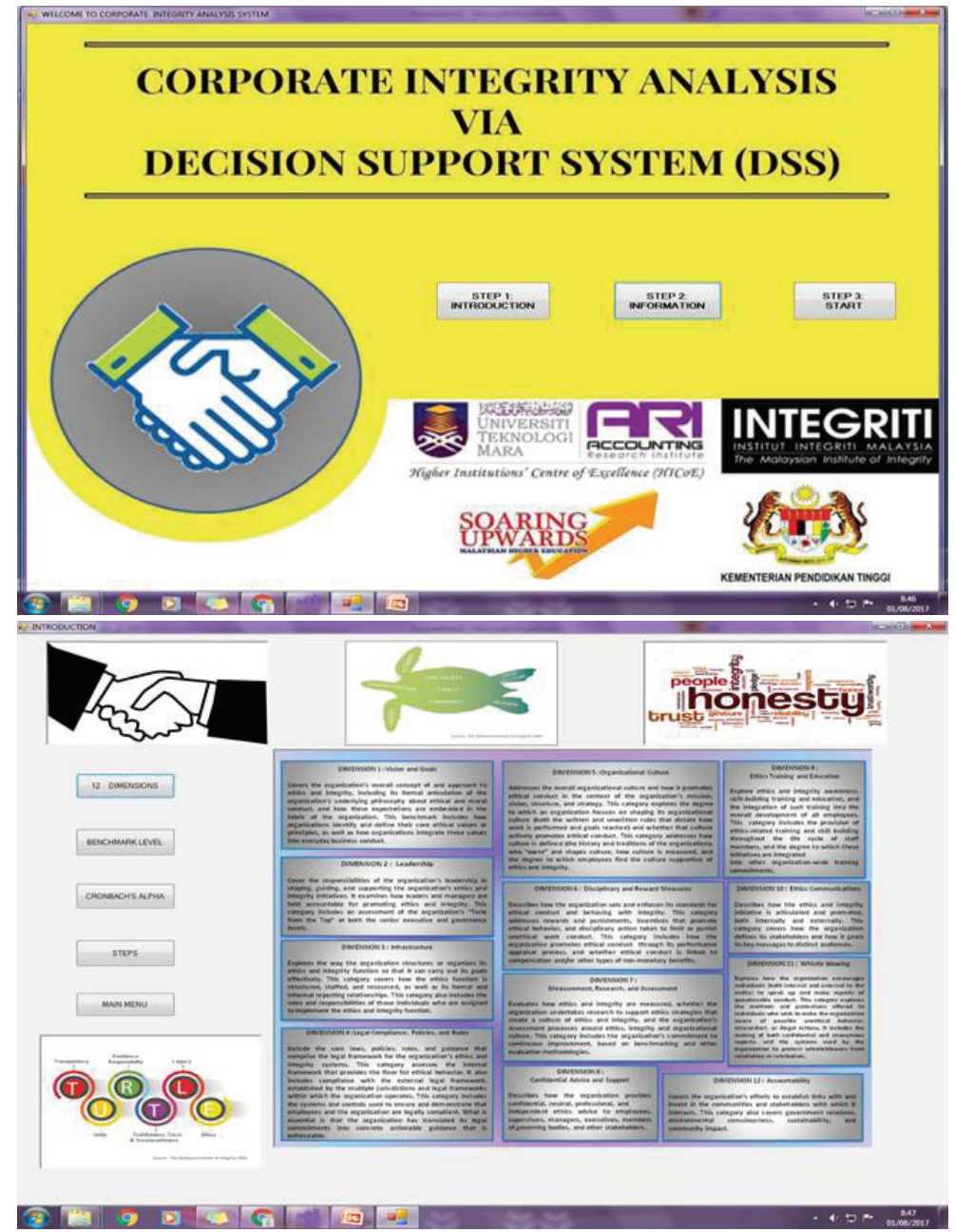

Figure 4: General Layout and Menu of the DSS 

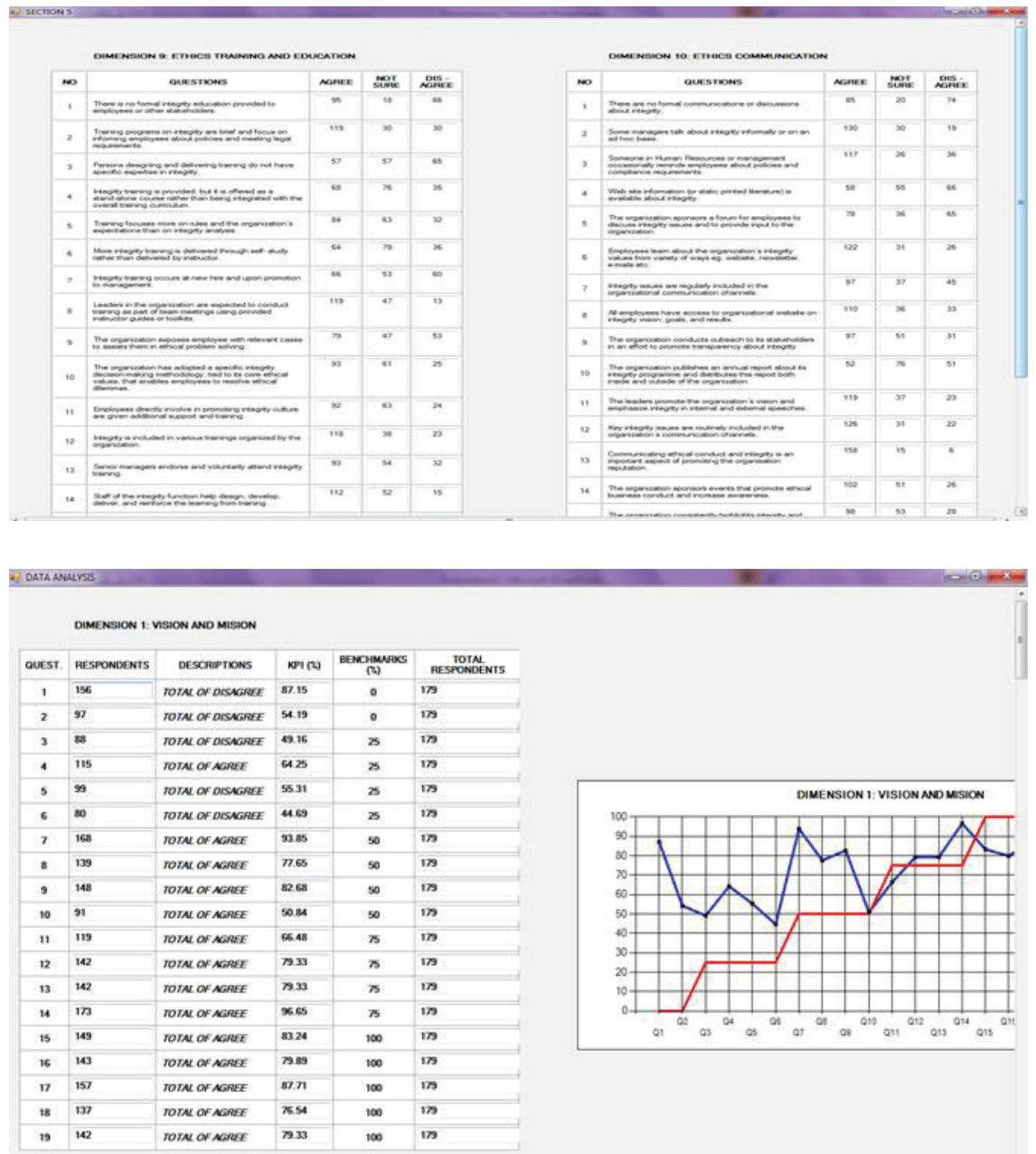

Figure 5: Graphical User Interface Results of the DSS Implementation

From the graph, the red line represents the GEIB data and the blue line represents organizational data. The organization data above the GEIB data, shows that it is good and vice versa. On the contrary, any data below the GEIB would need to be dealt with individually with respect to the specific dimension and questions being asked. As this study employed an expert system in its methodology, the DSS is intelligent enough to analyse and perform its decision-making tasks as shown in Figure 6. This figure shows the summary of the overall mean scores for Organization A. 


\begin{tabular}{|c|c|}
\hline DIMENSIONES & MEN SCOFES \\
\hline DMEENSION I: VISON MND MISION & nos \\
\hline DMRENSION 2 LENEERSIEP & $6 \pi$ \\
\hline 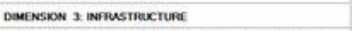 & 5253 \\
\hline 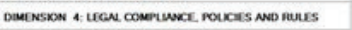 & 67.88 \\
\hline 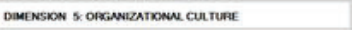 & 57.10 \\
\hline DEMENSIOW E DISCIPUINURY NND REWNRO MEASUAES & 5065 \\
\hline 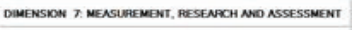 & 4565 \\
\hline DDMENSIOH a CONFIDENTWL NOUCE NAD SUPPORT & 49 \\
\hline 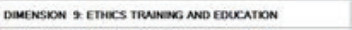 & 4.83 \\
\hline DARENSION 10: ETHICS CONMUUNICATION & 55.33 \\
\hline DARENSTON 11: Whastue Blownes & 467 \\
\hline DMAENSKOW IZ NCCOUNTNEUUTY & $54: 28$ \\
\hline
\end{tabular}

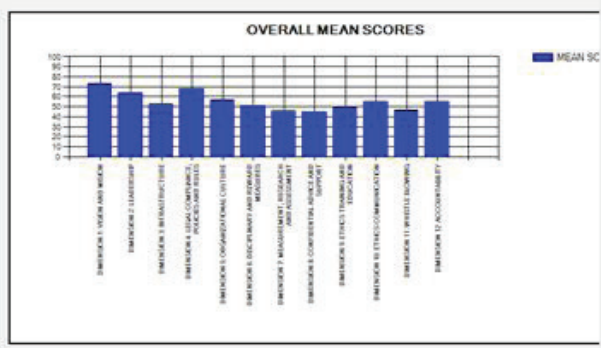

seck

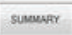

Figure 6: Overall Mean Scores for Organization A

Based on Figure 6, it was found that Organization A achieved their highest score on Dimension 1(Vision and Goals), while the lowest score was on Dimension 8 (Confidential Advice and Support) which was scored at $45 \%$. This finding is in agreement with the previous work by Zainal, Som and Mohamed (2019). The other lower scores are namely; Dimension 7 (Measurement, Research and Assessment) which was scored at 46\% and Dimension 11 (Whistle Blowing) which was scored at $47 \%$. The overall performance for this organization is $55 \%$. In addition, the system has recommended a few suggestions in order to improve the current implementation stage of ethics and integrity in the organization. Firstly, the organization should arrange a private office facility to provide for ethics advice and counselling. Secondly, a private office shall be outside of the operational chain of command. Thirdly, all calls and inquires seeking for ethics and integrity advice should be handled in confidence. Fourthly, an integrity officer should be encouraged to cross-check his/her advice with the legal officer. Fifthly, an annual report on ethics and integrity should be published, regularly. Sixthly, regular assessment on ethical conduct, legal compliance and leadership commitment towards ethical action should be performed, regularly. Lastly, the impact and return on investment of all components of its integrity initiatives should be communicated at all levels in the organization. 


\section{CONCLUSION}

In conclusion, organization A has an integrity level of $55 \%$, i.e. band of $50 \%$ to $75 \%$, which means they are currently moving towards strategic implementation of ethics and integrity at the work place. There were some limitations experienced during this study. Since the questionnaires used a 5-point Likert scale, there were times when respondents were biased which led them to their personal judgments. Besides that, the demographic section was still in the development stage during this study. In future work, the same demographic section should be used to analyze the results in more detail. The findings can be useful in providing awareness to the citizens to adopt good governance in a manner in which the integrity environment is put in place in their organizations.

\section{ACKNOWLEDGEMENTS}

The authors wish to extend their gratitude to the Malaysian Ministry of Higher Education and Institute of Research Management and Innovation (IRMI), Universiti Teknologi MARA for the financial support through 600-IRMI 5/3/GIP (044/2019). The authors would also like to thank the Accounting Research Institute (ARI) and Faculty of Chemical Engineering, Universiti Teknologi MARA for the supports given.

\section{REFERENCES}

Arnott, D., Pervan, G., Donnell, P. O., \& Dodson, G. (2000). An Analysis of Decision Support Systems Research : Preliminary Results. Decision Support in an Uncertain and Complex World: The IFIP TC8/WG8.3 International Conference 2004, 25-38.

Dubinsky, J., Richter, A. 2008. Global Ethics and Integrity Benchmark, QED Consulting Group (USA).

McDevitt, A. (2014). Local Integrity System. Transparency International. Retrieved from https://www.transparency.org/whatwedo/ publication / local_integrity_system_assessment_toolkit 
MIMOS Malaysian Integrity Test ( Mi-PBT MIT ). (2013). Retrieved June 1, 2017, from http://www.mimos.my/wp-content/uploads/2014/11/ Fact_Sheet_Mi-PBT_MIT_001-1015A.pdf

Mohamad Noor, N. M., Ab Hamid, S. H., Mohemad, R., Abdul Jali, M. @ M., \& Hitam, M. S. (2015). A review on a classification framework for supporting decision making in crime prevention. Journal of Artificial Intelligence, 8(1), 17-34.

Sajari, A., Haron, H., \& Ismail, I. (2016). Role of Chief Integrity Officer in Malaysian Public Sector. The National Conference for Postgraduate Research, University Malaysia Pahang, 135-141.

Sajari, A., Haron, H., \& Ismail, I. (2017). Ethical Climate, Chief Integrity Officer and Level of Ethics and Integrity in Malaysian Public Sector. FGIC 1st Conference on Governance \& Integrity, (April), 297-307.

Siddiquee, N. A. (2010). Combating corruption and managing integrity in Malaysia: A critical overview of recent strategies and initiatives. Public Organization Review, 10(2), 153-171.

Zainal, R., Som, A. M., Mohamed, N. (2017). A review on computer technology applications in fraud detection and prevention. Management \& Accounting Review, 16(2), 59-72.

Zainal, R., Som, A. M., \& Mohamed, N. (2019). A comparative study on the implementation stage of corporate integrity in the Malaysian Public Sectors. Religacion. Revista de Ciencias Sociales y Humanidades, 4(17), 693-700. 